\title{
Fabrication of Novel Amperometric Sensor for the Detection of Zinc Metal as an Environment Pollutant
}

\author{
HARISH KUMAR* and NEETU \\ Department of Chemistry, Ch. Devi Lal University, Sirsa-125 055 (Haryana), India \\ harimoudgill@gmail.com
}

Received 19 August 2017 / Accepted 19 September 2017

\begin{abstract}
We have fabricated graphite, carbon nanotube (CNT) and conducting polymer (polyaniline) based electrochemical sensor for the detection of zinc metal as an environment pollutant. The electrochemical performance of amperometric sensor was tested by cyclic voltammetry, amperometry and linear sweep voltammetry experiments. The developed amperometric sensor displays good electrochemical activity towards the detection of zinc present in the environment. Storage and stability conditions were also tested. Fabricated non-enzymatic amperometric sensor was successfully used for the precise, sensitive and specific detection of zinc metal present as an environment pollutant.
\end{abstract}

Keywords: Amperometric sensor, Conducting polymer, Electrochemical biosensor, Environmental pollutant, Zinc

\section{Introduction}

The detection of metals as an environment pollutant proves to be very beneficial for mankind because like the other pollutants such as pesticides, household chemicals, the harmful metals represent a growing environment pollutant concern ${ }^{1,2}$. Environment contamination by the trace and toxic metals shows a major environmental pollution issue, which ended in an increasing demand for the sensitive and selective sensor ${ }^{3}$. Harmful metals that come out from the anthropogenic activities present in environment which is several times greater than the limits of necessary intake in the living beings ${ }^{4}$. The harmful metals get accumulated in the environment and enter in the food chain of living beings which create a health risk for the living beings. Hence, early, easy and quick detection of harmful metals present in the environment becomes very important ${ }^{5,6}$. If the harmful metals are taken up by the living organism by the ingestion or inhalation they cause the nausea, vomiting and diarrhea ${ }^{7,8}$. The harmful metals also responsible for the long-term disease like cancer and damage to the central nervous system ${ }^{9,10}$. Figure 1 shows impact of zinc metal on the life of human beings if taken in excess.

There is several analytical methods available for the detection of metals like inductively coupled plasma with mass spectrometry, atomic absorption spectrophotometer, flame photometer, gravimetric and stripping voltammetry. All these methods have their own 
limitations and are time consuming and convoluted. To overcome these limitations, there is urgent need to fabricate amperometric sensor which is a rapid technique, provide the accurate information, portable and cost effective analytical method ${ }^{11}$. For a definitive electrochemical biosensor there is need of a suitable receptor in the recognition layer, the receptor is a molecule that binds the marked object ${ }^{12-17}$. In the last few decades, there has been reported many applications of conducting polymers ${ }^{18-20}$. Conducting polymers cast a strong and penetrable surface this behave as a transducer to convert the chemical interaction between the receptor and target analyte into an electric signal ${ }^{21-24}$. Due to its flexible nature and high order of conductivity, conducting polymer could be grafted on the surface of any conducting and non-conducting support ${ }^{25,26}$.

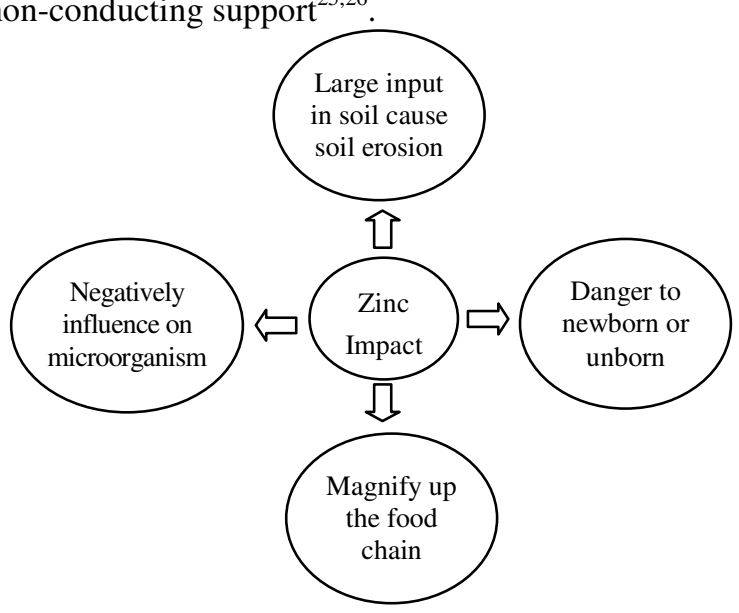

Figure 1. Impact of zinc metal on the life of human being if taken in excess amount

In continuation to our earlier study ${ }^{27-30}$, in this paper, we have focused on the fabrication of graphite, carbon nanotube and conducting polymer based electrochemical sensor for the detection of zinc metal as an environment pollutant.

\section{Experimental}

5.0 $\mathrm{M}$ of aniline is dissolved in the $1.0 \mathrm{M}$ solution of the protonic acid. The temperature was maintained between 1.0 to $4.0{ }^{\circ} \mathrm{C}$. The oxidant $\left(\mathrm{FeCl}_{3}\right)$ which is precooled is added drop wise to the ice-cold acidic solution of aniline. After sometime the colour of the polyaniline turns to dark green. The solution was continuously stirred for about 6.0 hours. The precipitate was washed with dilute $\mathrm{HCl}$ and then with the acetone and dried in vacuum oven maintained at constant temperature of $80.0{ }^{\circ} \mathrm{C}$ for 24.0 hours. It is notice that productivity of the polyaniline decreases after 5.0 hours hence in order to complete polymerization reaction, reaction time was increased to 8.0 hours.

\section{Preparation of the working electrode}

The carbon paste electrode was prepared by thoroughly mixing of rapheme, polyvinylpyrrolidone (PVP), carbon nanotube (CNT), conducting polymer (polyaniline), paraffin and potassium ferrricynide and was homogenized in an agate mortar using a pestle to obtain the paste. The paste was then packed tightly into the glass electrode in order to avoid entrapping of air in to the matrix. A copper wire then inserted externally in order to establish electrical connection with the electrochemical workstation. For every reading, the outer surface of the electrode having copper wire was renewed by polishing with the emery paper 
The cyclic voltammetric experiments were carried out by using $\mathrm{Fe}(\mathrm{CN})_{6}{ }^{3-}$ as an electrochemical probe. Phosphate buffer solution was prepared by using sodium chloride, potassium chloride, disodium phosphate, potassium di-hydrogen phosphate and double distilled water. The prepared electrode was rinsed several times with the sodium acetate buffer solution. For every reading, the surface of electrode was renewed by removing some amount of paste. The working electrode was stored at $4.0^{\circ} \mathrm{C}$ in dark place. Figure 2 shows schematic diagram of conducting polymer modified graphite polarizable electrode.

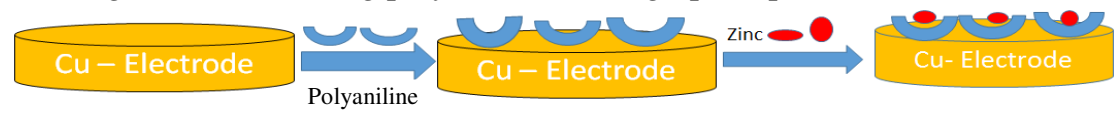

Figure 2. Schematic diagram showing working of conducting polymer modified graphite polarizable electrode

\section{Results and Discussion}

\section{Characterization of the polyaniline}

The synthesized polyaniline was characterized by UV-Visible, Fourier transform infrared (FT-IR) spectroscopy and x-ray diffraction (XRD) spectroscopic techniques.

\section{$U V$-Visible spectra of the polyaniline}

The absorption spectra of the polyaniline may be due to multiple distribution of the quinoid and benzenoid ring along the polyaniline backbones, different substituents, different products resulted from possible side reactions, cyclization, conformation effects and reduction in ring symmetry ${ }^{31}$. Figure 3 shows the UV-Visible spectra of polyaniline as a function of wavelength. The UV-Visible absorption spectra shows band at $329 \mathrm{~nm}$.

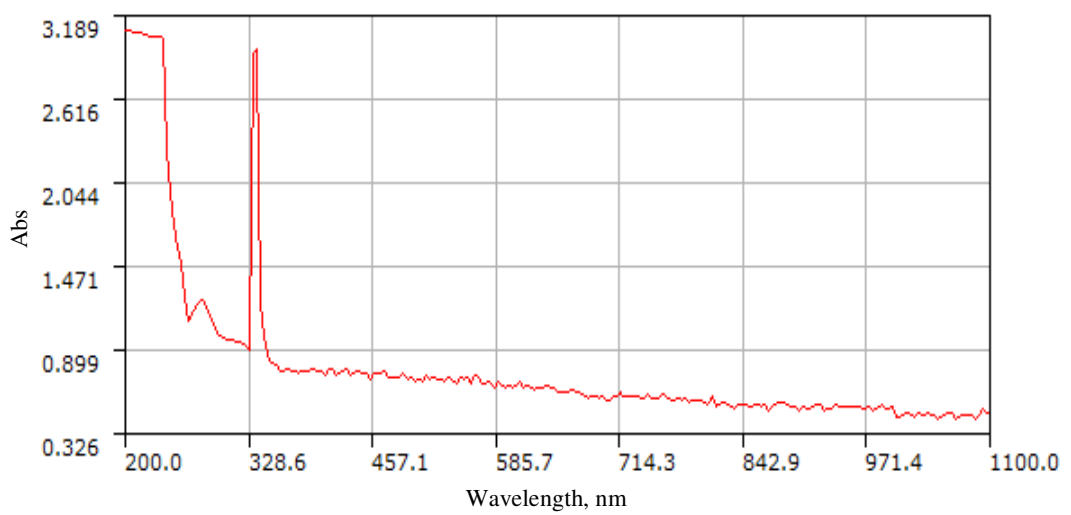

Figure 3. UV-Visible absorption spectra of polyaniline

\section{FT-IR spectroscopy of polyaniline}

FT- IR studies have been carried out for the characterization of the polymeric film using FT-IR spectrometer having the resolution in the range $450-4000 \mathrm{~cm}^{-1}$. FT-IR absorption spectra of the polyaniline is shown in Figure 4. The bands related to N-H stretching of an aromatic amine $(\mathrm{N}-\mathrm{H})$ appears in the region of $3691.7 \mathrm{~cm}^{-1}$ and this is attributed to the free $\mathrm{N}-\mathrm{H}$ stretching vibrations. The bands of the $-\mathrm{NH}_{2}$ group assigned to the asymmetric and symmetric stretching. The bands corresponding to $\mathrm{C}=\mathrm{N}$ and $\mathrm{C}=\mathrm{C}$ for the quinonoid and the benzanoid unit occurs at the 1600 and $1579 \mathrm{~cm}^{-1}$. The fingerprint region of the polyaniline appears $466.77 \mathrm{~cm}^{-1}$ to the $420.48 \mathrm{~cm}^{-1}$. 


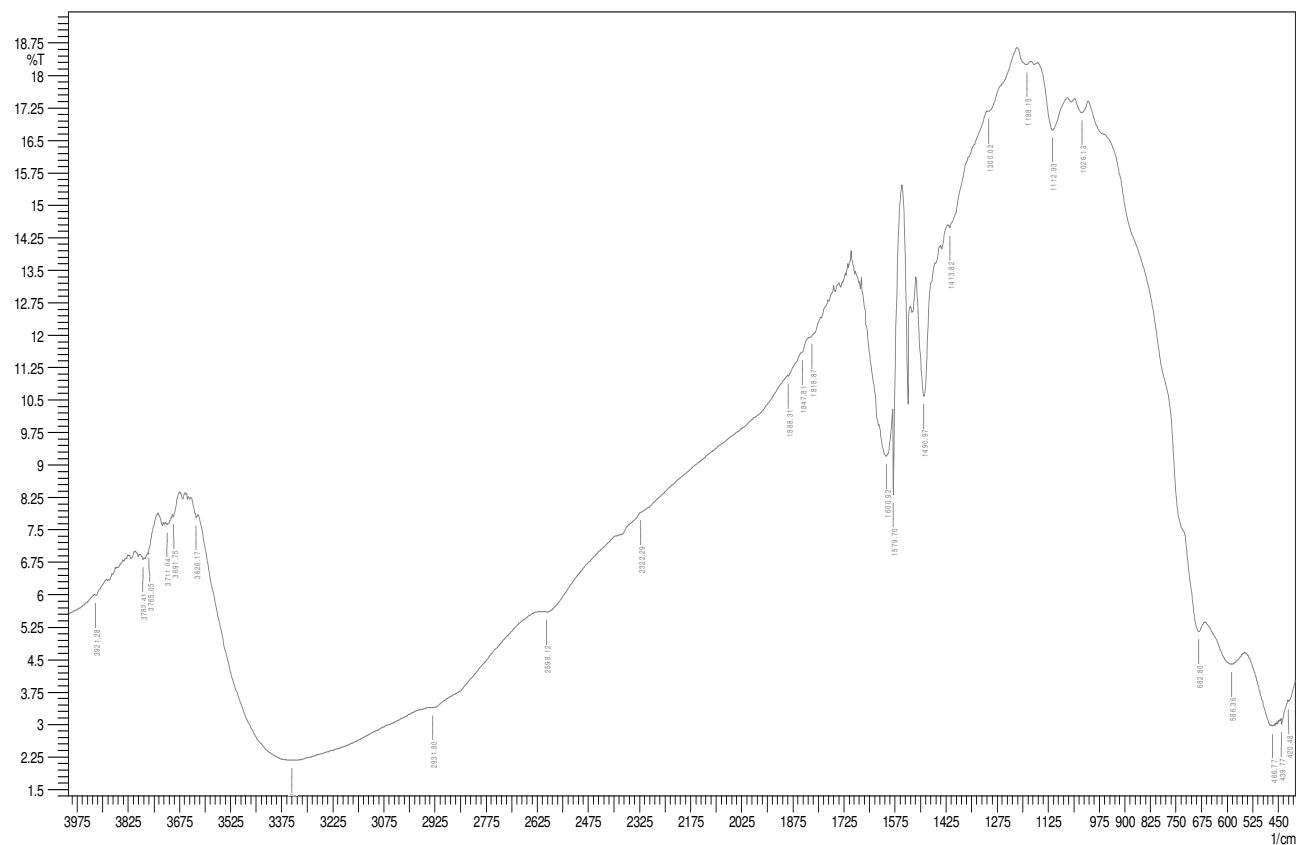

Figure 4. FTIR spectra of polyaniline

\section{XRD Analysis}

$\mathrm{X}$-ray diffraction pattern of PANI (polyaniline) is shown in Figure 4 . The peak around $25^{\circ}$ is the characteristic of $\pi$ conjugation in PANI. PANI is only partially crystalline with conducting metallic islands separated by large amorphous regions as evident from the XRD spectrum. The diffraction peak of the PANI occurs between the 10 to 40 degree due to the parallel and the perpendicular periodicity of the polymer ${ }^{32}$. There is the presence of benzenoid and the quinoid rings in the PANI chain makes the low crystalline nature of the conducting polymer ${ }^{33}$. The XRD pattern of the polyaniline shows a broad peak at $2 \theta=37.8$ degree which shows the amorphous nature of PANI in its emeraldine salt form ${ }^{34}$. The interplanar distance and crystalline size are estimated by Bragg's law and Debye-Scherer equation $^{35}$. During the oxidation of the aniline monomer the presence of initial acidic medium highly affects the crystallization which increases metallic character in the polyaniline ${ }^{36}$. Figure 5 shows $x$-ray diffraction pattern of conducting polymer polyaniline.

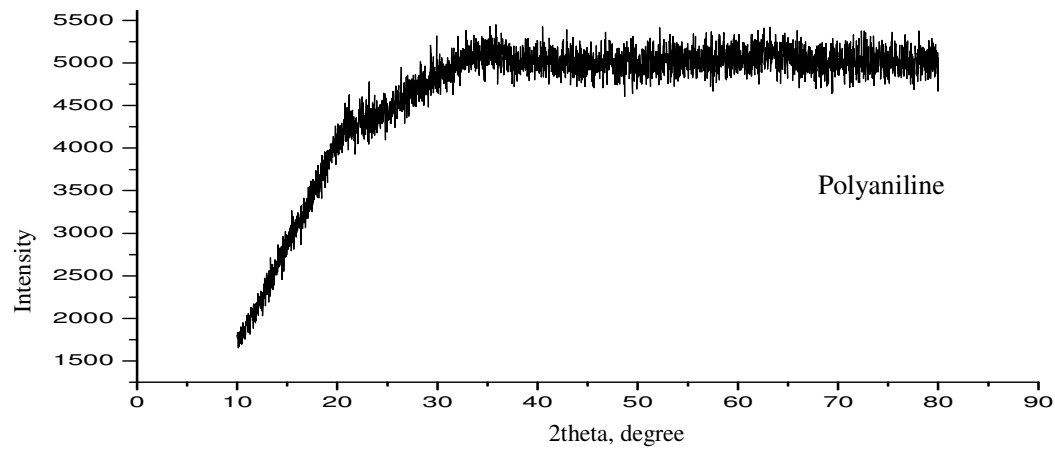

Figure 5. X-ray diffraction pattern of conducting polymer polyaniline 


\section{TEM Analysis}

The needle-shaped or nano web structures are seen in TEM image of polyaniline (Figure 6). It is reported that the organic precursor of aniline can be converted into electronically conductive carbon through pyrolysis processes at high temperatures ${ }^{37}$. In this process of synthesis of polyaniline, probably carbons are produced from the oxidation process of aniline, which may increase the conductivity of polyaniline. Average particle size of polyaniline was observed to be $30.0 \mathrm{~nm}$.

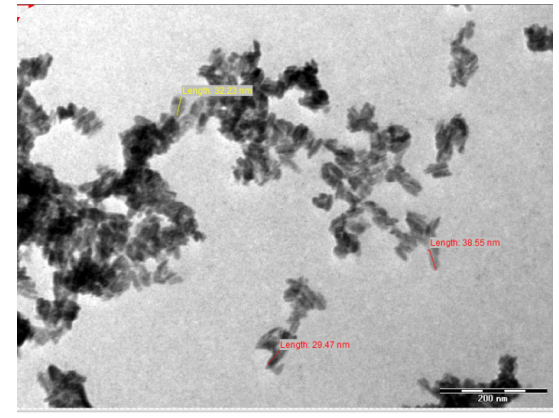

Figure 6. TEM image of conducting polymer polyaniline (PANI)

All the electrochemical measurements were performed using a Palmsens electrochemical interface, Netherland.

\section{Cyclic voltammetry for the detection of zinc metal in the environment}

The cyclic voltammetry experiments were performed to detect zinc metal with the help of specially designed and fabricated conducting polymer, CNT (Carbon nanotube) and graphite based working electrode. Platinum wire was used as auxiliary electrode and $\mathrm{Ag}, \mathrm{AgCl} / \mathrm{KCl}_{\text {sat }}$ as a reference electrode. The electrode surface was preliminary treated by polishing, degreasing with alcohol and ultrasonic cleaning. The analyte (hydrazine) displays a reversible $\mathrm{CV}$ which is observed when all the initial analyte can be recovered after a forward and reverse scan cycle. The CV was performed with the help of conducting polymer, CNT and Graphite powder modified electrode in the PBS solution containing zinc. We observed a large peak shaped zinc oxidation current at $2.3 \mathrm{~A}$ at a potential of $1.14 \mathrm{~V}$. Figure 7 shows cyclic voltammogram resulting of reversible reduction and oxidation of $1.0 \mathrm{mM}$ zinc at a bare electrode from spectrally pure graphite, carbon nanotube and polyaniline based amperometric sensor at a $\mathrm{pH}$ of 6.5 at room temperature and scan rate of $0.01 \mathrm{Vs}^{-1}$ in the phosphate buffer solution (PBS).

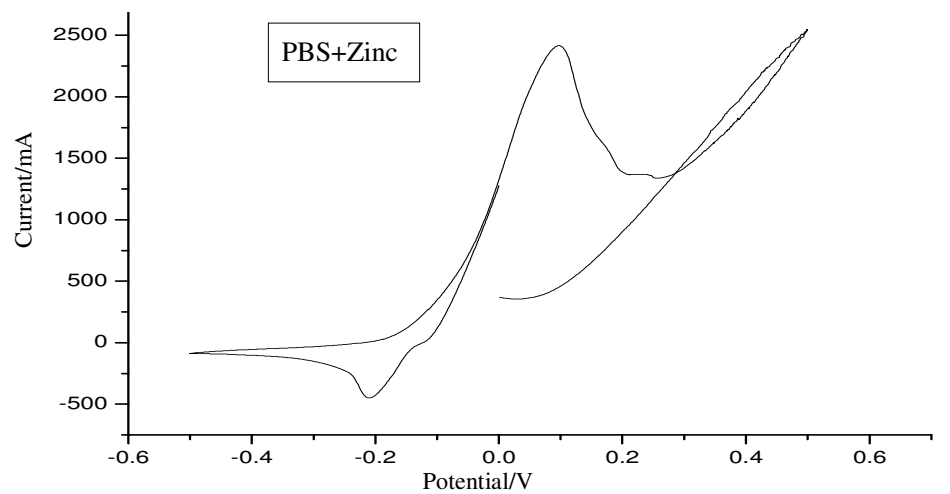

Figure 7. Cyclic voltammetry for the detection of zinc metal in the environment 


\section{Linear sweep voltammetric experiment for the detection of zinc}

Linear sweep voltammetric experiments were performed in order to study the electrochemical behavior of the working electrode ${ }^{38,39}$. It is observed from the linear sweep experiments (Figure 8) that value of current increases continuously up to $0.17 \mathrm{~V}$ and then starts decreasing upto $0.6 \mathrm{~V}$. Value of limiting anodic peak current $\mathrm{I}_{\mathrm{pa}}$ was found to $3.8 \mathrm{~A}$ for $1.0 \mathrm{mM}$ of zinc.

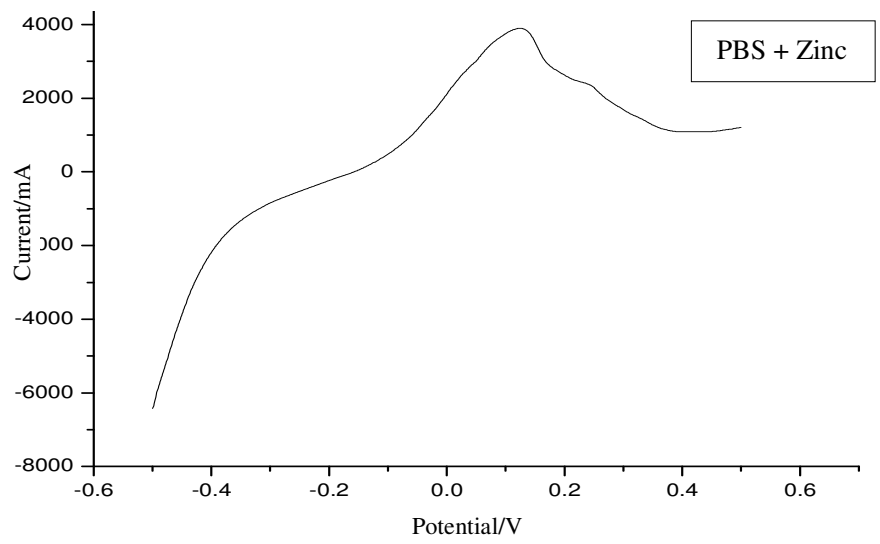

Figure 8. Linear sweep voltammetric experiment for the detection of zinc

\section{Ampereometric detection of zinc}

Amperometry experiments were performed at fixed potential i.e. OCP (Open circuit potential) against $\mathrm{Ag}, \mathrm{AgCl} / \mathrm{KCl}_{\text {sat }}$ as a reference electrode. Variation of current $(\mathrm{mA})$ with time (s) was investigated at constant potential. It is observed from the amperometric experiments (Figure 9) that the value of current first decreases and then becomes constant. The fabricated amperometric sensor shows that response current decreases linearly between 2.0 to $0.15 \mathrm{~mA}$ with time. It is observed that in the absence of zinc, there is no anodic and cathodic oxidative and reductive current peak ${ }^{40}$. This behavior shows a strong and irreversible adsorption of the analyte on the surface of the electrode.

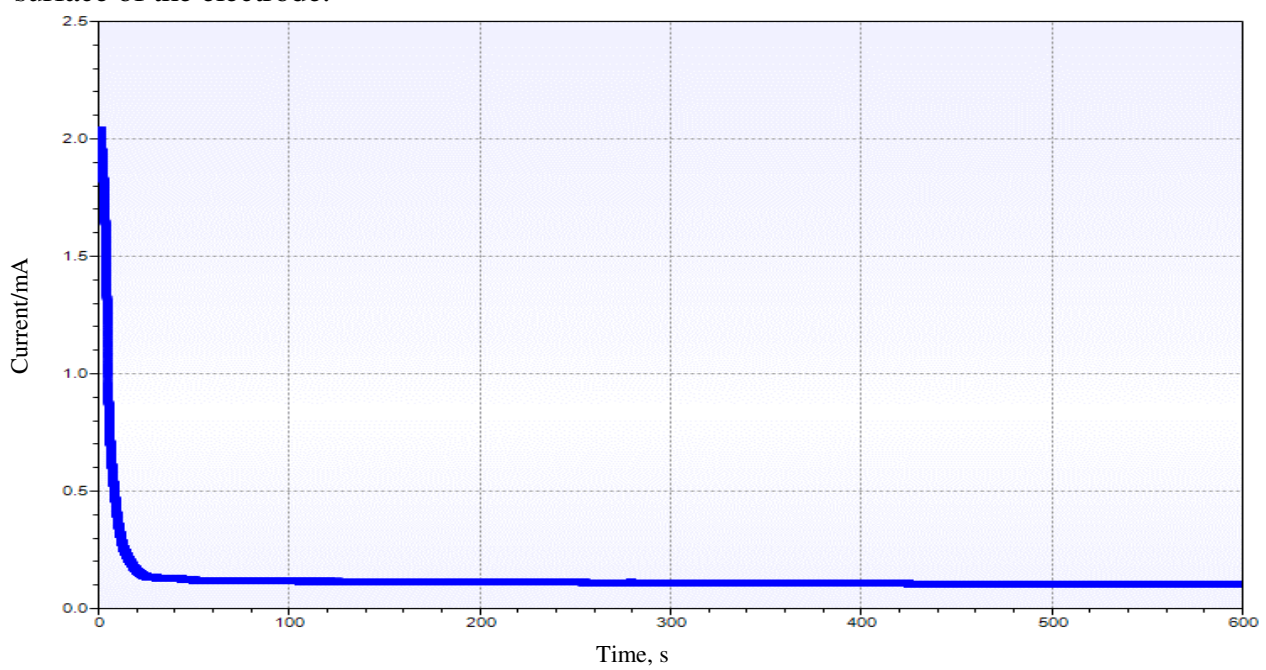

Figure 9. Amperometric study showing variation of the current with respect to time 


\section{Selectivity, Reproducibility and Storage stability}

The selectivity of conducting polymer-carbon nanotube-graphite carbon electrode (CP-CNTGCE) towards zinc under the optimum condition was studied for a number of potential interference. The good reproducibility and excellent storage stability gave an opportunity to $\mathrm{CP} / \mathrm{CNT} / \mathrm{GCE}$ as promising electrocatalyst for electrochemical techniques determination of zinc. For this the electrodes were stored at refrigerated condition $4.0{ }^{\circ} \mathrm{C}$ and used periodically for the analysis of zinc at an interval of five days. The sensor response of electrode was fairly stable even after 40 days of storage.

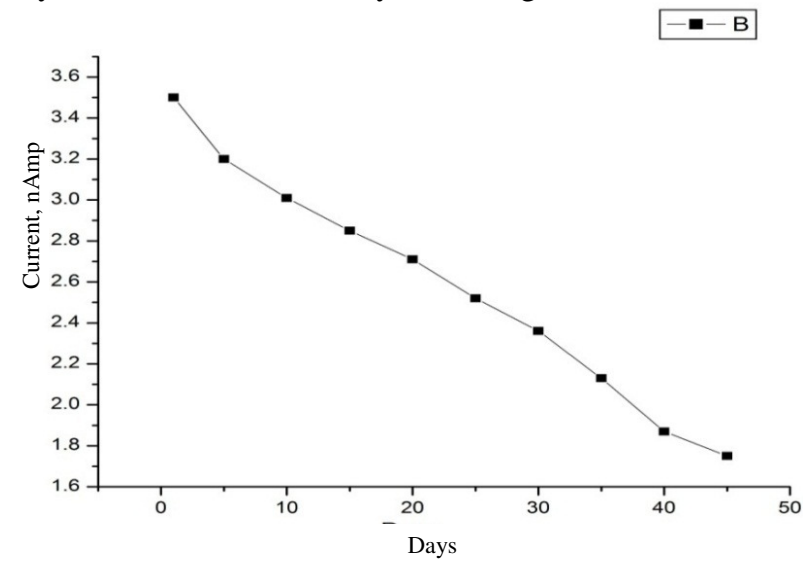

Figure 10. Effect of storage time on the response of working electrode based amperometric sensor in $0.1 \mathrm{M}$ sodium phosphate buffer, $\mathrm{pH} 7.0$ at a temperature of $4.0^{\circ} \mathrm{C}$.

\section{Conclusion}

(Standard assay conditions were used for each assay)

Fabricated non enzymatic graphite powder, CNT and conducting polymer based amperometric sensor were tested for its electrochemical performance for detecting environment pollutants. The integration of graphite, carbon nanotube and conducting polymer into this amperometric sensor brings new strategies for enhancing their electrochemical performance. The electrochemical performance of the electrode was tested by cyclic voltammetry, ampereometry and linear sweep voltammetry experiments. Value of limiting anodic peak current $\mathrm{I}_{\mathrm{pa}}$ was found to $3.8 \mathrm{~A}$ for $1.0 \mathrm{mM}$ of zinc. A large peak shaped zinc oxidation current was found to be $2.3 \mathrm{~A}$ at a potential of $1.14 \mathrm{~V}$. Selectivity, reproducibility and storage stability of the electrode was also tested for 40 days. The method was successfully used for the precise, sensitive, selective, easy and fast electrochemical technique for determination of zinc metal as an environment pollutant.

\section{References}

1. Luca P, David E, Karine G S, Mathilde F, Audrey R and Pierre G, Front Chem., 2014, 2, 19; DOI:10.3389/fchem.2014.00019

2. Bogdan F, Ioana B, Ionel F, Didier F, Cecilia C, Florence G, Robert S and Iuliu H, Int J Electrochem Sci., 2015, 10, 121-139.

3. Wang Z M, Guo H W, Liu E, Yang G C and Khun N W, Electroanalysis, 2010, 22(2), 209-215.

4. Georgette R, José C, Nancy O, Alia M and Eduardo T, Biocatalysis, 2016, 1(1), DOI:10.1515/boca-2015-0010 
5. Ninwong B, Chuanuwatanakul S, Chailapakul O, Dungchai W and Motomizu S, Talanta, 2012, 96, 75-81; DOI:10.1016/j.talanta.2012.03.057

6. Pandey S K, Singh P, Singh J, Sachan S, Srivastava S and Singh S K, Electroanalysis, 2016. 28(10), 2472; DOI:10.1002/elan.201600173

7. Gao $\mathrm{C}$ and Huang X J, TrAC Trends Anal Chem., 2013, 51, 1-12; DOI:10.1016/j.trac.2013.05.010

8. Long X X, Yang X E and Ni W Z, J Appl Ecol., 2002, 13, 757.

9. Martin S and Griswold W, Environ Sci Technol Br Cit., 2009, 15, 1-6.

10. Prabhakar S, Singh A K and Pooni D S, Ind J Anim Sci., 2012, 82, 244.

11. Long F, Zhu A, Shi H, Wang H and Liu J, Scientific Reports 3, Article number: 2308, 2013.

12. Subramanian V and Jerzy R, Pol J Food Nutr Sci., 2008, 58(2), 157-164.

13. Ling S W and Chieh W C, Int J Environ Sci Develop., 2014, 5(3), 270-273; DOI:10.7763/IJESD.2014.V5.490

14. Luca P, David E, Karine G, Mathilde F, Audrey R and Pierre G, Front Chem., 2014, 2, 19; DOI:10.3389/fchem.2014.00019

15. Jane E and Frew H, Allen, Hill Inorganic Chemistry Laboratory, University of Oxfad, South Parks Road Oxfad OX1 3QR. United Kingdom.

16. Badihi-Mossberg M, Buchner V and Rishpon J, Electroanalysis, 2007, 19(19-20), 2015-2028.

17. Miroslav P and Petr S, J Appl Biomed., 2008, 6(2), 57-64.

18. Belanger D, RenX, Davey J, Uribe F and Gottesfeld S, J Electrochem Soc., 2000, 147(8), 2923-2929; DOI:10.1149/1.1393626

19. Snook G A, Kao P and Best A S, J Power Sources, 2011, 196(1), 1-12; DOI:10.1016/j.jpowsour.2010.06.084

19. Maleki N, Absalan G, Safavi A and Farjami E, Anal Chim Acta, 2007, 581(1), 37-41; DOI:10.1016/j.aca.2006.08.043

20. Ewelina S, Pawe Krzyczmonik and Awomira Skrzypek S, Sensing in Electroanalysis, 2013, 8, 315.

21. Oztekin Y, Ramanaviciene A, Yazicigil Z, Solak A O and Ramanavicius A, Biosens Bioelectron., 2011, 26(5), 2541-2546; DOI:10.1016/j.bios.2010.11.001

22. Kumar J B and Retna R C, Anal Chem., 2008, 80(13), 4836-4844; DOI:10.1021/ac071064w

23. Dhand C, Das M, Datta M and Malhotra B D, Biosens Bioelectron., 2011, 26(6), 2811-2821; DOI:10.1016/j.bios.2010.10.017

24. Popović N, Jugović B, Jokić B, Knežević-Jugovć Z, Stevanović J, Grgur B and Gvozdenović M, Int J Electrochemical Sci., 2015, 10, 1208-1220.

25. Malenahalli H N, Nanjanagudu G G and Yoon-B S, Applied Materials Today, 2017, 9, 419-433; DOI: 10.1016/j.apmt.2017.09.001

26. Oztekin Y, Yazicigil Z, Solak A.O, Ustundag Z, Okumus A, Kilic Z, Ramanaviciene A and Ramanavicius A, Sens Actuat B, 2012, 166-167, 117-127;

DOI:10.1016/j.snb.2012.01.025

27. Kumar H and Rani R, Sci Progress, 2013, 96(3), 294-308.

28. Kumar H and Bhawana, Elixir International J., 2016, 90, 37565.

29. Kumar H and Bhawana, Ind J Advances Chem Sci., 2016, 4(2), 130-137.

30. Kumar H and Bhawana, Res J Chem Sci., 2015, 5(12), 88-97.

31. Prakash T, Narayan D S and Prem Nazeer K, Bull Mater Sci., 2002, 25(6), 521-526; DOI:10.1007/BF02710542 
32. Amir Mostafaei and Ashkan Zolriasatein, Prog Nat Sci., Mat Int., 2012, 22(4), 273 280; DOI:10.1016/jpnsc.2012.07.002

33. ShiL,Wang X,LuL, Yang X and Wu X, Syn Met., 2009, 159(23-24), 2525-2529; DOI:10.1016/j.synthmet.2009.08.056

34. Liu A, Bac L H, Kim J S, Kim B K and Kim J C, J Nanosci Nanotech., 2013, 13(11), 7728-7733; DOI:10.1166/jnn.2013.7831

35. Ahmad A, Esah H, Zaharah I and Hashim S, Materials, 2012, 5, 1487, DOI:10.3390/ma5081487

36. Shokry Hassan H, Elkady M F, Abd El Kawi M A, Alian M F, Amm J Appl Chem., 2015, 3(3-1), 54, DOI:10.11648/j.ajac.s.2015030301.18

37. Huang J X, Virji S, Weiller B H and Kaner R B, J Am Chem Soc., 2003, 125(2), 314315; DOI:10.1021/ja028371y

38. Khun N W and Liu E, Electrochimica Acta, 2009, 54(10), 2890-2898;

DOI:10.1016/j.electacta.2008.11.014

39. Rekha G Solanki, Ind J Pure Appl Phys., 2010, 48, 133-135.

40. Palanisamy S, Cheemalapati S and Chen S M, Int J Electrochem Sci., 2012, 7, 8394-8407. 